\title{
An Insight into the Influence of Donor Compensating Defects in Doped $\mathrm{ZnO}$ Thin Films*
}

\author{
S. GHOSH AND D. BASAK ${ }^{\dagger}$ \\ School of Physical Sciences, Indian Association for the Cultivation of Science, Jadavpur, Kolkata-700032, India \\ (Received November 14, 2018; revised version April 5, 2019; in final form April 11, 2019)

\begin{abstract}
Herein, we report a study on the role of acceptor-like $\mathrm{V}_{\mathrm{Zn}}$ (zinc vacancy) donor compensating defects in $\mathrm{ZnO}$
\end{abstract} \\ by studying In and Sn doped RF magnetron sputtered $\mathrm{ZnO}$ thin films prepared under exactly similar growth and \\ post-growth annealing conditions. Sn dopants in $\mathrm{ZnO}$ films have been activated largely as evidenced by a more than \\ two orders of magnitude increase in the carrier concentration as compared to the as-grown films while In dopants \\ are activated by only 7 times after a post-growth annealing in excess Zn. Interestingly, an enhanced mobility due \\ to annealing further strengthen the feasible compensation between the dopants and the acceptor-like defects.
}

DOI: 10.12693/APhysPolA.135.467

PACS/topics: zinc vacancy, donor compensating defects, doped $\mathrm{ZnO}$ thin films, mobility, Urbach energy

\section{Introduction}

Transparent although highly conducting oxide thin films have great importance in various transparent electronic devices [1]. Doped $\mathrm{ZnO}$ thin film is a strong candidate to fullfill the above criteria due to its wide bandgap $\left(E_{g}=3.37 \mathrm{eV}\right.$ at room temperature) with additional advantages of its low cost and non-toxicity. The free carrier concentration can be modulated over one or more orders of magnitude by varying the dopant type, its concentration, and post-growth annealing process. However, efficiency of dopant is limited due to formation of donor compensating point defects [2]. Coulombic interactions between the dopant and acceptor-like defects, such as oxygen interstitial $\left(O_{i}\right)$ and zinc vacancy $\left(V_{Z n}\right)$, lead to bound complexes [3-6]. Furthermore, it is shown that these complexes, rather than isolated impurities, dominate the electrical properties of trivalent cation doped $\mathrm{ZnO}$. It is thus appealing to study the impact of variable valence dopant on the electrical properties of doped $\mathrm{ZnO}$ thin films.

In this work, nominally 0.7 at.\% In and $\mathrm{Sn}$ doped $\mathrm{ZnO}$ films have been deposited using RF magnetron sputtering technique and subjected to post-growth annealing treatments under exactly similar conditions. We show that while both In and Sn dopants have been activated by a post-growth annealing process in the presence of excess $\mathrm{Zn}$, the free carrier density has been increased enormously in case of Sn. Interestingly, an enhanced mobility due to annealing strengthen the possible relation between these dopants with the acceptor-like defects.

\footnotetext{
* Presented on: 10th International Workshop on Zinc Oxide and Other Oxide Semiconductors, September 11-14, 2018, Warsaw, Poland

${ }^{\dagger}$ corresponding author; e-mail: sspdb@iacs.res.in
}

\section{Experimental}

In (IZO) and $\mathrm{Sn}$ (SZO) doped $\mathrm{ZnO}$ thin films have been deposited by a RF magnetron sputtering (Rocky mountain vacuum tech. model: RMS T-4065) instrument on cleaned glass substrates at $500^{\circ} \mathrm{C}$ using nominally 0.7 at.\% In and $\mathrm{Sn}$ doped $\mathrm{ZnO}$ ceramic targets. The targets were prepared by proportionate mixing of $\mathrm{In}_{2} \mathrm{O}_{3}$ (purity $>99.9 \%$ ) and $\mathrm{SnO}_{2}$ (purity $>99 \%$ ) powders separately with $\mathrm{ZnO}$ (purity > 99\%) powder using a ceramic approach. The details of the deposition process have been reported earlier [7]. The films with thickness of $\approx 350 \mathrm{~nm}$ were further annealed at $550^{\circ} \mathrm{C}$ for 1 hour separately in a reducing $\left(\mathrm{Ar}+10 \% \mathrm{H}_{2}\right)$ with and without excess $\mathrm{Zn}$ ambient [7]. The films are named as IZO AG, IZO AM, IZO Zn for IZO series, and SZO_AG, SZO_AM, SZO_Zn for SZO series, respectively for as-grown, annealed in reducing ambient without and with excess $\mathrm{Zn}$. The crystalline phase of the thin films were first confirmed by X-ray diffractometry (XRD; X'pert Pro, PANalytical) using $\mathrm{Cu} K_{\alpha_{1}}$ $(\lambda=1.5406 \AA)$ radiation. The optical transmission spectrum were recorded using a UV-vis spectrophotometer (Varian; model: Cary-5000). Surface roughness of the films has been investigated using the atomic force microscope (AFM; VEECO model: diCP-II). The values of resistivity, carrier concentration, and mobility at room temperature were measured in the Van der Pauw geometry by a Hall effect measurement system (HEMS, Nano Magnetic Instruments) using four probe technique. For the Hall measurement, $\mathrm{Al}$ contacts of diameter $1 \mathrm{~mm}$ with thickness around $80 \mathrm{~nm}$ were deposited by thermal evaporation on top of the films in the Van der Pauw geometry.

\section{Results and discussions}

In Fig. 1a and b, the XRD peak at around $34.2^{\circ}$ corresponds to the (002) peak of the hexagonal wurtzite structure of $\mathrm{ZnO}$ indicating that the crystallites dominantly 

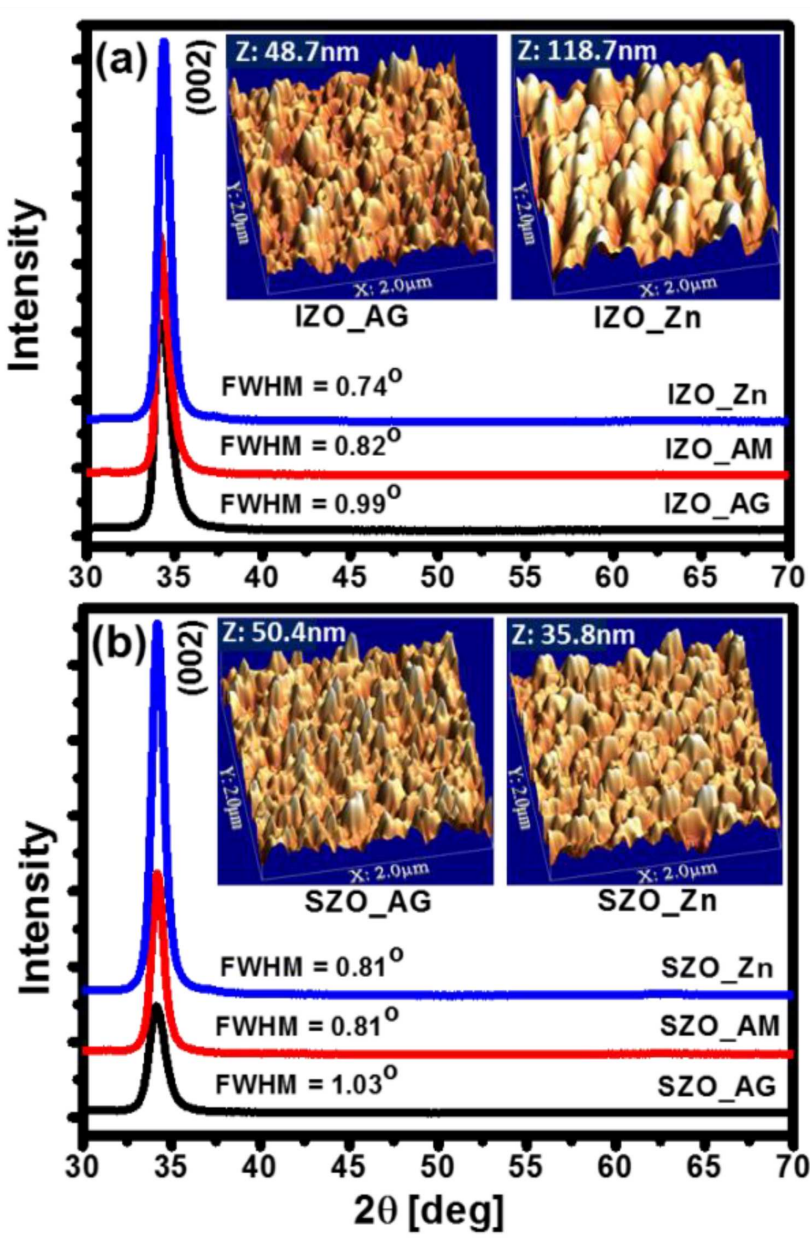

Fig. 1. XRD patterns of (a) IZO and (b) SZO films with respective FWHM values. The insets show corresponding AFM images.

orient along [001] direction. After annealing, the (002) peak position slightly shifts towards higher $2 \theta$ values as compared to the as-grown films probably due to a decrease in the strain. An enhancement in the (002) peak intensity and also a decrease in the full width at half maxima (FWHM) after annealing indicate better orientation and crystallinity. No other peak due to $\mathrm{In}_{2} \mathrm{O}_{3}$ or $\mathrm{SnO}_{2}$ has been observed indicating successful incorporation of the dopants in the $\mathrm{ZnO}$ lattice.

The insets in Fig. 1a and b show the 3D topological AFM images of the as-grown and a representative annealed film. It is quite clear from the AFM images that the spikes like grains join and become rounded off after annealing. The surface roughness values are $4.92 \mathrm{~nm}$ and $12.49 \mathrm{~nm}$ for IZO_AG and IZO_Zn, respectively, while these values are $\overline{4.9} \mathrm{~nm}$ and $4.3 \overline{8} \mathrm{~nm}$ for $\mathrm{SZO} A G$ and SZO_Zn, respectively.

The transmission spectra for IZO and SZO films in Fig. 2a and $\mathrm{b}$ show sharp band-edge absorptions below $400 \mathrm{~nm}$ and high transparency of $85-90 \%$ in the visible region. The optical band-gap $\left(E_{g}\right)$ of IZO and SZO films have been evaluated by using the Tauc plots [8].
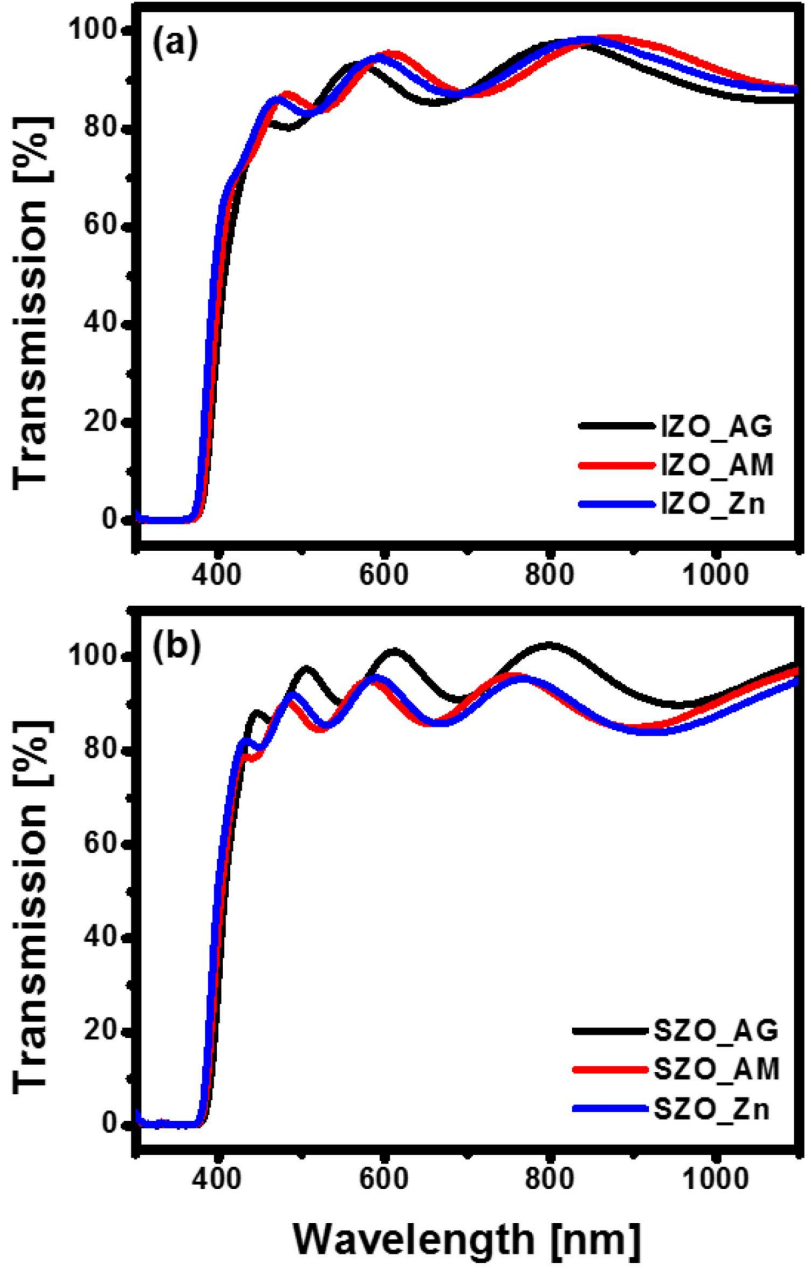

Fig. 2. Transmission spectra of (a) IZO and (b) SZO films.

The band gap values are at par with the previous reports $[9,10]$. There is an increase in the band-gap value with an increase in carrier concentration for both the dopants as well as the annealing processes (Fig. 3a and $\mathrm{b}$ and Table I) due to the Burstein-Moss effect [11]. The Urbach energy $\left(E_{u}\right)$ designates the width of band tails of a localized state closely related to disorder in the crystalline lattice. This value has been obtained from the inverse of the slope of the linear part of the plot of $\ln (\alpha)$ versus photon energy $(h \nu)$ (where $\alpha$ is the absorption coefficient) [12]. Figure 3 shows that for both IZO and SZO films, the $E_{u}$ values follow a trend: $E_{u-A G}>E_{u-A M}>E_{u-\mathrm{Zn}}$ and change inversely with the band-gap value [11]. A decrease in the $E_{u}$ value indicates an improvement in the optical quality of the films due to a decrease in the structural defects after postgrowth annealing, upgrading being more in case of excess Zn treatment. The values of resistivity, mobility, and carrier concentrations of IZO and SZO films are shown in Table I. In doping leads to a resistivity of $3.86 \times 10^{-1} \Omega \mathrm{cm}$, a carrier concentration value of $4.42 \times 10^{19} \mathrm{~cm}^{-3}$ and a very low mobility of $3.65 \times 10^{-1} \mathrm{~cm}^{2} /(\mathrm{V} \mathrm{s})$ for IZO AG. 

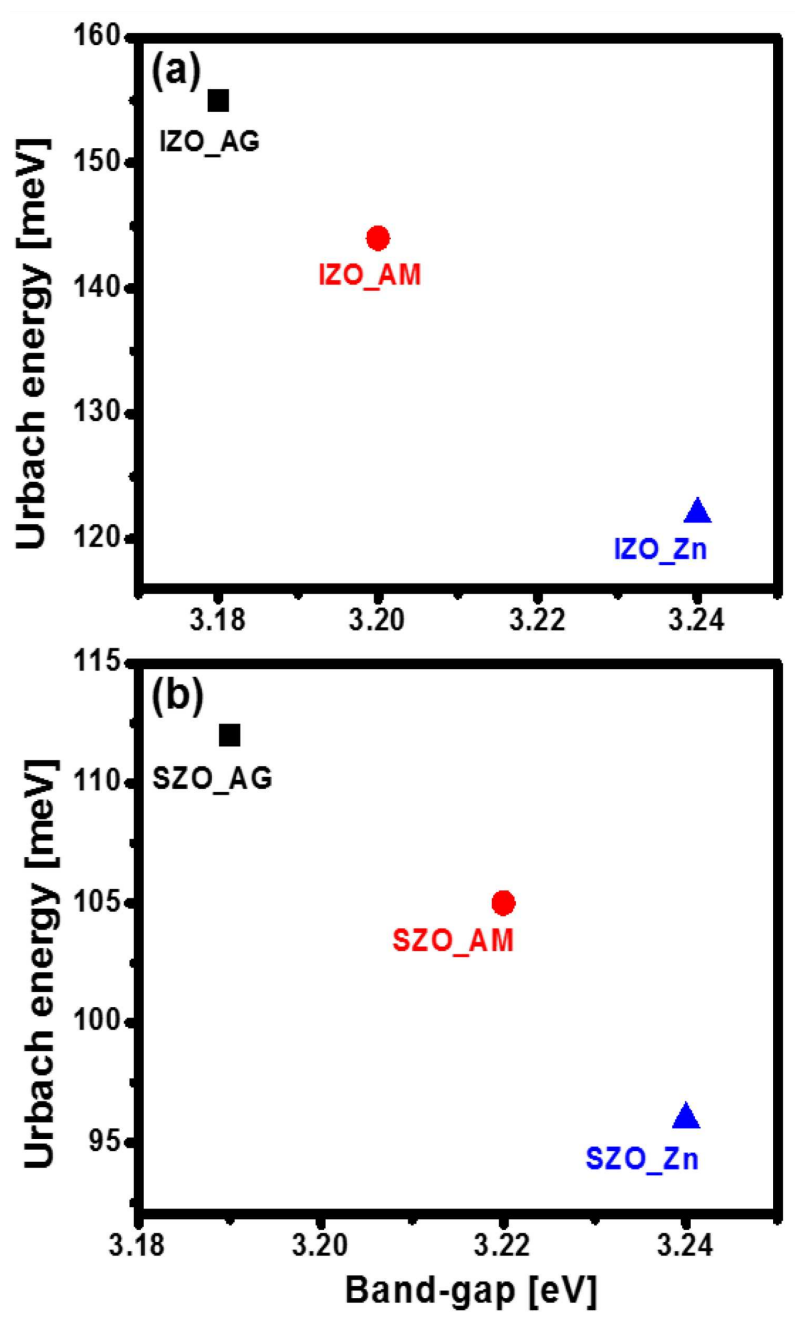

Fig. 3. Urbach energy vs. band-gap plots of (a) IZO and (b) SZO films.

While Sn doping leads to a very high resistivity value of $5.58 \times 10^{3} \Omega \mathrm{cm}$ and the carrier concentration value of SZO AG could not be measured due to a measurement limitation of the present instrument i.e $1 \times 10^{17} \mathrm{~cm}^{-3}$. Therefore, we assume that the carrier concentration of SZO_AG is less than $1 \times 10^{17} \mathrm{~cm}^{-3}$. It is expected that when $\mathrm{ZnO}$ is doped by tetravalent dopants instead of trivalent ones, its carrier concentration would be more in as-grown films. Highly resistive films due to Sn doping have also been reported previously $[13,14]$. Therefore, the mechanism of $\mathrm{Sn}$ doping in $\mathrm{ZnO}$ is not as simple as In dopants. Occupancy of $\mathrm{Sn}^{2+}$ at $\mathrm{Zn}$ sites or $\mathrm{Sn}^{4+}$ at $\mathrm{Zn}$ sites causing complex defect formation with $\mathrm{V}_{\mathrm{Zn}}$ [15] should not lead to an increase in the carrier concentration. In our Sn doped films, some $\mathrm{Sn}^{4+}$ ions are probably causing more charge compensation by making a complex defect or $\mathrm{Sn}^{0}$ is likely to be present in SZO film [16]. The low mobility value for the films may also be due to the contribution of grain boundary scattering [17]. The resistivity value decreases while the carrier concentration, as well as mobility values increase after annealing for both IZO and SZO films. Though, an increase in carrier concentration has been observed for IZO films, a tremendous improvement has been observed in case of SZO films after both the annealing processes. The ratios of the carrier concentrations of the annealed film and the respective as-grown films gives us an estimation of carrier activation $(\eta)$ in each doping cases. Although the $\eta$ values are increased by 4.8 and 7 times for annealed IZO films, an enormous increase in the $\eta$ values (the exact values could not be calculated but estimated as more than two orders of magnitude) is observed in case of annealed SZO films.

Additionally, there is a 6 times increase in the value for SZO Zn with respect to SZO AM which imply more activation occurs in the former case. For annealing in reducing ambience (without excess $\mathrm{Zn}$ ) films, there is a probability of reduction of $\mathrm{O}_{i}$ related acceptor-like defects increasing the carrier concentration [3]. However, annealing in excess $\mathrm{Zn}$ causes $\mathrm{Zn}$ diffusion through $\mathrm{V}_{\mathrm{Zn}}$ by decrease of acceptor-like compensating defects and increase of the conductivity of the films [7]. Enhanced mobility rules out the probability of formation of zinc interstitial $\left(\mathrm{Zn}_{i}\right)$ defects (carrier scattering defects) [7].

TABLE I

Resistivity, mobility, carrier concentration, band-gap, and ratio of carrier concentration of the annealed films to the as-grown films. $\eta$ - ratio of carrier concentration of the annealed films to the as-grown films.

\begin{tabular}{|c|c|c|c|c|c|}
\hline Sample & $\begin{array}{c}\text { Resistivity } \\
{[\Omega \mathrm{cm}]}\end{array}$ & $\begin{array}{l}\text { Mobility } \\
{\left[\mathrm{cm}^{2} /(\mathrm{V} \mathrm{s})\right]}\end{array}$ & $\begin{array}{c}\text { Carrier } \\
\text { concentration } \\
{\left[\mathrm{cm}^{-3}\right]}\end{array}$ & $\begin{array}{l}\text { Band-gap } \\
\left(E_{g}\right)[\mathrm{eV}]\end{array}$ & $\eta$ \\
\hline IZO_AG & $3.86 \times 10^{-1}$ & $3.65 \times 10^{-1}$ & $4.42 \times 10^{19}$ & 3.18 & - \\
\hline $\mathrm{IZO}_{-}^{-} \mathrm{AM}$ & $3.93 \times 10^{-3}$ & 7.39 & $2.14 \times 10^{20}$ & 3.2 & 4.84 \\
\hline $\mathrm{IZO}_{-} \mathrm{Zn}$ & $2.2 \times 10^{-3}$ & 9.13 & $3.11 \times 10^{20}$ & 3.24 & 7.04 \\
\hline $\mathrm{SZO}_{-} \mathrm{AG}$ & $5.58 \times 10^{3}$ & - & $<1.0 \times 10^{17}$ & 3.19 & - \\
\hline $\mathrm{SZO}_{-}^{-} \mathrm{AM}$ & $7.62 \times 10^{-1}$ & $7.14 \times 10^{-1}$ & $1.15 \times 10^{19}$ & 3.22 & - \\
\hline $\mathrm{SZO}_{-} \mathrm{Zn}$ & $5.17 \times 10^{-2}$ & 1.76 & $6.85 \times 10^{19}$ & 3.24 & $\begin{array}{l}6 \text { times higher } \\
\text { than SZO_AM }\end{array}$ \\
\hline
\end{tabular}


So due to annealing in excess $\mathrm{Zn}$ ambient, activation of the carriers occurs via reduction of $\mathrm{V}_{\mathrm{Zn}}$ related acceptorlike complexes. Therefore, interestingly, dopant activation is more in case of SZO over IZO films after postgrowth annealing. Further studies are in progress to investigate the compensation effect by various dopants including pentavalent dopants which will be reported in future.

\section{Conclusions}

Sn dopants in $\mathrm{ZnO}$ films are compensated heftily. A post-growth annealing in reducing ambience with excess $\mathrm{Zn}$, causes a highly increase in the carrier concentration as compared to a only 7 times increase in case of In dopants owing to reduction of acceptor-like defects. Our results help to develop an understanding on the role of various dopants and acceptor-like defects in $\mathrm{ZnO}$ thin films.

\section{Acknowledgments}

One of the authors, Mr. S. Ghosh would like to thank CSIR, India for providing the fellowship.

\section{References}

[1] K. Ellmer, Nat. Photon. 6, 809 (2012).

[2] M.K. Taha, O. Boisron, B. Canut, P. Melinon, J. Penuelas, M. Gendry, B. Masenelli, $R S C A d v$. 7, 28677 (2017).

[3] A. Bikowski, T. Welzel, K. Ellmer, Appl. Phys. Lett. 102, 242106 (2013).
[4] D.C. Look, T.C. Droubay, S.A. Chambers, Apl. Phys. Lett. 101, 102101 (2012).

[5] D.O. Demchenko, B. Earles, H.Y. Liu, V. Avrutin, N. Izyumskaya, U. Ozgur, H. Morkoc, Phys. Rev. B 84, 075201 (2011).

[6] D. Sett, D. Basak, J. Phys. Chem. C 121, 24495 (2017).

[7] S. Ghosh, A. Mallick, B. Dou, M.F.A.M. van Hest, S.M. Garner, D. Basak, Sol. Energy 174, 815 (2018).

[8] J.C. Tauc, Optical Properties of Solids, NorthHolland, Amsterdam 1972, p. 372.

[9] M. Kapilashrami, C.X. Kronawitter, T. Torndahl, J. Lindahl, A. Hultqvist, W.C. Wang, C.L. Chang, S.S. Mao, J. Guo, Phys. Chem. Chem. Phys. 14, 10154 (2012).

[10] Y. Caglar, S. Ilican, M. Caglar, F. Yakuphanoglu, Spectrochim. Acta A 67, 1113 (2007).

[11] B.E. Sernelius, K.F. Berggren, Z.C. Jin, I. Hamberg, C.G. Granqvist, Phys. Rev. B 37, 10244 (1988).

[12] F. Urbach, Phys. Rev. 92, 1324 (1953).

[13] H. Sato, T. Minami, S. Takata, J. Vac. Sci. Technol. A 11, 2975 (1993).

[14] C.Y. Tsay, H.C. Cheng, Y.T. Tung, W.H. Tuan, C.K. Lin, Thin Solid Films 517, 1032 (2008).

[15] S. Venkataraj, S. Hishita, Y. Adachi, I. Sakaguchi, K. Matsumoto, N. Saito, H. Haneda, N. Ohashi, J. Electrochem. Soc. 156, H424 (2009).

[16] A. Mallick, S. Sarkar, T. Ghosh, D. Basak, J. Alloys Comp. 646, 56 (2015).

[17] K. Ellmer, R. Mientus, Thin Solid Films 516, 5829 (2008). 